http://jmscr.igmpublication.org/home/ ISSN (e)-2347-176x ISSN (p) 2455-0450 crossref DOI: https://dx.doi.org/10.18535/jmscr/v8i3.84

\title{
To Study the Relationship between HIV Infection and Tubercular Manifestation with Level of Immunosuppresion and Duration of Illness
}

\author{
Authors \\ Shoaib Mehboob ${ }^{1}$, T.P. Singh ${ }^{2}$, Prashant Prakash ${ }^{3}$, Abhishek Raj ${ }^{4}$ \\ ${ }^{1}$ Junior Resident PG Department of Medicine SNMC Agra \\ ${ }^{2}$ Professor, PG Department of Medicine SNMC Agra \\ ${ }^{3}$ Associate Professor and Unit Head of Pulmonary Medicine PG Department of Medicine SNMC Agra \\ ${ }^{4}$ Associate Professor, Government Medical College Banda
}

\begin{abstract}
Introduction: Mycobacterium tuberculosis infection is one of the most common opportunistic infection associated with HIV in India.It is estimated that nearly $60-70 \%$ of HIV positive individuals will develop tubercular infection in their lifetime. It is one of the leading causes of death in HIV infected individuals. Manifestation of tuberculosis infection are extremely variable in HIV infected individuals and depends upon the level of immunosuppression and duration of illness. Around 1.8 million new cases of tuberculosis occur annually in India and similarly the estimated pool of HIV infection is approximately 2.5 million. Therefore there is always increased risk of synergistic interaction between the two diseases.

Objective: To study manifestation of Tubercular infection in HIV/AIDS patient and its relationship with CD4 count i.e. level of immunosuppression and relationship with duration of disease.

Method: It was a prospective study done in Sarojini Naidu Medical College, Agra over a period of 18 months. All the patient who fulfilled the inclusion criteria and gave consent were included in the study

Result: We studied 106 HIV positive patients diagnosed with tuberculosis (pulmonary and extrapulmonary). It was observed that the prevalence of pulmonary tuberculosis was much higher than extrapulmonary tuberculosis $(59.43 \%$ vs $40.57 \%)$ in HIV infected patients. The mean CD4count for pulmonary and extrapulmonary tuberculosis were 238/cumm and 117/cumm respectively. It was also observed that as the duration of illness increases the risk of getting extrapulmonary tuberculosis increases despite having same CD4 count. In pulmonary tuberculosis smear negative cases (55.56\%) were more common than smear positive cases. Fever was the most consistent symptom and in chest $x$-ray upper lobe infiltration and non-cavitary lesion were more common.

Conclusion: Through this study we concluded that the incidence of tubercular infection increases with the decreasing level of immunosuppression and risk of extra pulmonary tuberculosis increases with increasing duration of illness.
\end{abstract}

\section{Introduction}

Mycobacterium tuberculosis infection is one of the most common opportunistic infection associated with HIV in India. It is estimated that nearly $60-70 \%$ of HIV positive individuals will develop tubercular infection in their lifetime. It is one of the leading cause of death in HIV infected individuals. Manifestation of tuberculosis infection are extremely variable in HIV infected individuals and depends upon the level of 
immunosuppression and duration of illness. Around 1.8 million new cases of tuberculosis occur annually in India and similarly the estimated pool of HIV infection is approximately 2.5 million $^{2}$. Therefore there is always increased risk of synergistic interaction between the two diseases.

HIV infections favours epidemic of tuberculosis in multiple ways. It suppresses the immune response and lead to progression of latent infection to active TB. Studies from Indi have reported HIV seropositivity rates varying from 0.4 to $20.1 \%$. Tuberculosis can occur at any stage of HIV disease, and its manifestations depend largely on the degree of immunosuppression. The aim of the present study was to record the clinical, radiological profile of pulmonary and extrapulmonary tuberculosis (EPTB) in HIVseropositive person with level of immunosuppression and duration of disease.

HIV-1 infection alters the course of $\mathrm{M}$. tuberculosis infection and substantially increases the risk of active tuberculosis (TB). Tubercular infection increases levels of HIV-1 viral DNA through various processes like replication, propagation and genetic diversity. Therefore, coinfection provides reciprocal advantages to both pathogens. $^{2}$

There is approximately fourfold risk of TB in patients infected with HIV-1 treated with antiretroviral therapy (ART). HIV-1 infects $\mathrm{CD}^{+} \mathrm{T}$ cells and macrophages. Mycobacterium tuberculosis primarily infects macrophages, which require $\mathrm{CD}^{+} \mathrm{T}$ cells to augment intracellular clearance of microbial pathogens. The depletion of $\mathrm{CD}^{+} \mathrm{T}$ cells due to HIV-1 infection plays a major role in the increased risk of $\mathrm{TB}$ in this individuals. $^{3}$

\section{Method}

This prospective study was carried out from 1March 2018 to September 302019 in Sarojini Naidu medical college Agra. After institutional ethical committee approval 106 patients with HIV and Tuberculosis co-infected attending ART centre, general OPD and indoor of PG department of medicine, S.N. Medical College, Agra constituted the material of present study.

Thorough history was taken and all patients were properly investigated and further followed till end of study.

Following patient were excluded from study-

- Chronic smoker

- HIV infected patient with diabetes mellitus.

- HIV infected person taking any immunosuppressive drug like steroid for long duration.

- Tuberculosis diagnosed before diagnosis of HIV.

\section{Results-}

The findings were discussed under following heading:

\section{1) Demographic}

Males were affected more than females (62\% vs $38 \%$ ). Majority of patients were in age group of 30-40 years.

\section{2) Pulmonary vs extrapulmonary tuberculosis}

In our study we found that pulmonary tuberculosis was more common than extrapulmonary tuberculosis. (59.43\% vs $40.57 \%$ ).

\section{3) Relationship with CD4 count-}

Mean CD4 count for pulmonary tuberculosis was much higher than for extrapulmonary tuberculosis.

Table 1- Showing Mean CD4 count

\begin{tabular}{|l|c|c|c|c|}
\hline $\begin{array}{l}\text { CD4 } \\
\text { count }\end{array}$ & $\begin{array}{c}\text { EPTB- } \\
\text { AB }\end{array}$ & $\begin{array}{c}\text { EPTB- } \\
\text { LN }\end{array}$ & $\begin{array}{c}\text { Extra } \\
\text { pulmonary } \\
\text { CNS }\end{array}$ & Pulmonary \\
\hline Mean & 162.14 & 165.53 & 117.29 & 238.19 \\
\hline SD & 78.98 & 85.48 & 79.94 & 128.33 \\
\hline
\end{tabular}

\section{4) Relationship with duration of illness}

As the duration of illness increases the risk of extrapulmonary tuberculosis increases. In our study majority of the patient having duration of illness between 3-5 years were diagnosed with pulmonary tuberculosis (61\%) and those with illness of duration more than 5 years were diagnosed with extrapulmonary tuberculosis. $(76 \%)$. 
(CD4 count removed as confounding factor by dividing into group of same range of $\mathrm{CD} 4$ count)

\section{Findings observed in pulmonary tuberculosis group.}

\section{Clinical features}

Table 2- Showing prevalence of symptoms in HIV positive pulmonary tuberculosis patients

\begin{tabular}{|l|c|c|}
\hline Clinical findings & No. & $\%$ \\
\hline Fever & 63 & 98.5 \\
\hline Cough & 59 & 93.65 \\
\hline Weight loss & 42 & 66.67 \\
\hline Decrease appetite & 35 & 55.56 \\
\hline breathlessness & 38 & 60.3 \\
\hline hemoptysis & 03 & $04.6 \%$ \\
\hline
\end{tabular}

Pulmonary $(\mathrm{N}=63)$

Fever was the most consistent symptoms $(98.5 \%)$ followed by cough $(93.65 \%)$ and weight loss $(66.67 \%)$.

\section{Sputum Examination}

Table 3- Showing the pattern of sputum examination for AFB in HIV positive tuberculosis

\begin{tabular}{|l|c|c|}
\hline Pulmonary & Sputum positive & Sputum negative \\
\hline No. & 21 & 43 \\
\hline$\%$ & $32.8 \%$ & $67.18 \%$ \\
\hline
\end{tabular}

Pulmonary $(\mathrm{N}=63)$

Sputum negative cases were more than sputum positive cases.

\section{Chest $x$-ray features}

Table 4 - Showing the radiological pattern in HIV positive pulmonary tuberculosis

\begin{tabular}{|l|c|c|}
\hline Radiology features & No. & $\%$ \\
\hline Infiltration & 41 & $65.64 \%$ \\
\hline Cavity & 7 & $10.9 \%$ \\
\hline Miliary & 13 & $20.3 \%$ \\
\hline Fibrosis & 3 & $4.6 \%$ \\
\hline
\end{tabular}

\section{Extra pulmonary tuberculosis}

\section{1) CNS Tuberculosis}

Table 5- Showing clinical finding observed in CNS tuberculosis $(\mathrm{N}=21)$

\begin{tabular}{|l|c|c|}
\hline Clinical findings & No. & $\%$ \\
\hline Fever & 21 & 100.00 \\
\hline Headache & 19 & 90.48 \\
\hline Vomiting & 17 & 80.95 \\
\hline Altered sensorium & 12 & 57.14 \\
\hline NR & 13 & 61.90 \\
\hline FND & 2 & 9.52 \\
\hline Seizure & 9 & 42.86 \\
\hline
\end{tabular}

Fever was the most consistent symptoms (100\%) followed by headache $(90 \%)$ and weight loss $(80.95 \%)$.

In radiological finding meningeal enhancement was seen in $52 \%$ cases, followed by tuberculoma in $38 \%$ cases and hydrocephalus in $23.81 \%$.

Analysis of cerebrospinal fluid showed pleocytosis (mean white cell count 154/cumm with mean lymphocyte percentage of $86.7 \%$ ), hypoglycorrhachia (mean glucose level, 46.14 $\mathrm{mg} / \mathrm{dl}$ ) and mean protein level of $185 \mathrm{mg} / \mathrm{dl}$.

\section{2) Abdominal Tuberculosis}

Table 6 Showing clinical features of abdominal tuberculosis in HIV patients $(\mathrm{N}=7)$

\begin{tabular}{|l|c|c|}
\hline Clinical findings & No. & $\%$ \\
\hline Fever & 7 & 100.00 \\
\hline Pain abdomen & 5 & 71.43 \\
\hline Altered bowel habit & 3 & 42.86 \\
\hline Ascites & 3 & 42.86 \\
\hline
\end{tabular}

Fever and abdominal pain were the main presenting complains followed by ascites and altered bowel bladder habit.

Ultrasonographic finding showed mesenteric lymphadenopathy in $71.4 \%$ cases, ascites in $42.8 \%$ and splenic abscess in $14.2 \%$ cases.

\section{3) Tubercular Lymphadenitis ( $\mathbf{N}=\mathbf{1 5})$}

Swelling (100\%) was the most common presenting symptoms followed by fever (80\%). Cervical region was the most common site involved. Discharging sinus was seen only in $33 \%$ cases.

\section{Discussion}

Mycobacterium tuberculosis is one of the leading cause of patients death worldwide. It was estimated that there were around 1.3 million death due to TB among HIV negative people and an additional 374000 death among HIV positive patients in 2016. HIV and Tuberculosis have been closely linked since the emergence of AIIDS ${ }^{4}$. .TB is one of the most common opportunistic infection affecting HIV seropositive individual and it remain the most common cause of death in patients with AIDS. 
There has been a significant rise in incidence of tuberculosis infection worldwide and HIV is one of the major contributory factor. Although with the availability of good antiretroviral therapy there has been a significant decrease in incidence of new HIV positive case however with advent of these drugs more people are living with HIV ,hence risk of spreading of infection increases along with increase in risk of TB infection .Recently, HIV estimate for India has been revised to less than half; however, most of this drop is not due to an actual decrease in HIV burden but due to availability of more reliable population-based data.. Maximum patients in our study were in the age group of 31-60 years and majority (69.7\%) were males.

Brig S K Sharma et al in a study EPTB in HIVpositive patients noted lymph node involvement as the most common EPTB site followed by spleen. ${ }^{5}$ The difference in our study could be because of adequate inclusion of hospitalized immunocompromised patients. Many of our patients were admitted with meningoencephalitis, pleural effusion, organomegaly and on investigations found to be immunocompromised. Hence our study is more representative as it has both in hospital and community-based data.

Ajay Jaryal, Rajeev Raina, Malay Sarkar, and Ashok Sharma (2011) similar study were performed they concluded that extrapulmonary tuberculosis were more common and commonest was CNS tuberculosis and majority of patients were having CD4 count less than 200/cmm. ${ }^{6}$

Magna Manjareeka ${ }^{a}$ Sitikantha Nanda (2013) In their study $44 \%$ had pulmonary tuberculosis and $56 \%$ had extrapulmonary tuberculosis. Majority of the patients were diagnosed between 5-8 year after diagnosis of HIV (47.62\%). Majority of patients (80.95\%) were having CD4 count less than 200/cumm. Mean CD4 count in this category was 117.29 cumm. $^{7}$

Though not many studies were performed in India, most of studies which have done shows extra pulmonary $\mathrm{TB}$ to be more common but in our studies pulmonary TB was more common. The data in our study was more community based as we included all patients which come under our inclusion criteria who landed to us in indoor or outdoor department.

\section{Conclusion}

Tuberculosis is the most common opportunistic infection in HIV infected individuals. As the level of immunosuppression increases the risk of acquiring tubercular infection increases. We recommend the screening of all patient for pulmonary tuberculosis in which CD4 count is less than 200/cumm. As the duration of illness increases the risk of extrapulmonary tuberculosis increases which is associated with higher morbidity and mortality. HIV infected individuals often have atypical manifestation physician should be aware of such atypical presentation and should raise suspicious of tuberculosis in such patients. Initiation of anti-tubercular drug early in the course markedly reduces morbidity and mortality.

\section{References}

1. Swaminathan $\mathrm{S}$, Ramachandran $\mathrm{R}$, Baskaran G, Paramasivan CN, Ramanathan U, Venkatesan P, Prabhakar R, Datta M. Risk of development of tuberculosis in HIV-infected patients. The International Journal of Tuberculosis and Lung Disease. 2000 Sep 1;4(9):839-44.

2. Sharma SK, Mohan A, Kadhiravan T. HIV-TB co-infection: epidemiology, diagnosis \& management. Indian J Med Res. 2005 Apr 1;121(4):550-67.

3. Walker NF, Meintjes G, Wilkinson RJ. HIV-1 and the immune response to TB. Future virology. 2013 Jan;8(1):57-80.

4. World Health Organization (WHO) Global tuberculosis control: Surveillance, planning, financing-WHO report 2009. Chapter1, Epidemiology. Document WHO/HTM/TB/2009.411. [Last cited on 2009]. Available from: http://www.who.int/tb/publications/global _report/2009/en . 
5. Jaryal A, Raina R, Sarkar M, Sharma A. Manifestations of tuberculosis in HIV/AIDS patients and its relationship with CD4 count. Lung India: official organ of Indian Chest Society. 2011 Oct;28 (4):263.

6. Jaryal A, Raina R, Sarkar M, Sharma A. Manifestations of tuberculosis in HIV/AIDS patients and its relationship with CD4 count. Lung India: official organ of Indian Chest Society. 2011 Oct; 28(4):263.

7. Manjareeka M, Nanda S. Prevalence of HIV infection among tuberculosis patients in Eastern India. Journal of infection and public health. 2013 Oct 1;6(5):358-62. 